\title{
Pluripoteny and Cancer, Two Sides of The Same Coin?
}

\section{Angel G Martin*}

StemTek Therapeutics, Bilbao, Spain

*Corresponding author: Angel G Martin, Parque Tencologico de Bizkaia, Edif. 612, C/Astondo Bidea, Derio 48160, Bizkaia, Spain, Tel: +34 666818653; Fax: 972-3-9253104; E-mail: agmartin@stemtektherapeutics.com

Rec Date: August 26, 2014, Acc Date: August 28, 2014, Pub Date: August 30, 2014

Copyright: $\odot 2015$ Martin AG. This is an open-access article distributed under the terms of the Creative Commons Attribution License, which permits unrestricted use, distribution, and reproduction in any medium, provided the original author and source are credited.

\section{Editorial}

Cancer and developmental biology scientists realized over a century ago that genes and pathways relevant to cancer overlap with embryonic development as reflected in the reactivation of embryonic genes during tumor progression. Consequently the question was raised of whether tumors could arise from transformation of tissue stem cells or "retro-differentiation" of more differentiated cells [1]. Nearly 40 years later, these ideas and questions are still hot spots in cancer research. The "retrodifferentation" concept can be now translated as cellular plasticity, a process by which non-stem differentiated cells can spontaneously acquire stem cell like characteristics [2]. This phenomenon has important implications for cancer therapy and a big impact on our current view of the cancer stem cell hypothesis.

Most solid tumors show a hierarchical organization at the cellular level with a small population of cancer stem-like cells responsible for tumor initiation and maintenance. However, this model does not imply that tumors are generated from transformed tissue stem cells. The target of transformation could be a tissue stem cell, a progenitor, or a differentiated cell that acquires self-renewal ability.

The process of in vitro pluripotency induction presents parallelisms with tumor generation. The mechanisms underlying the reprogramming process are not well understood yet; however the three main transcription factors Oct4, Sox 2 and Nanog, called master regulators of pluripotency, have proved responsible for maintaining the undifferentiated state. Basically both processes, reprograming and transformation, need the expression or activation of oncogenes (expression of Oct4, Sox 2 and Nanog has been repeatedly observed in tumors), inactivation of tumor suppressor genes, overriding the senescence and apoptotic barriers and both processes also involve epigenetic changes and a metabolic switch towards a glycolytic metabolism [3,4]. The tumor suppressor p53 poses a barrier for pluripotency induction [5]. Therefore it is tempting to speculate that the acquisition of the self-renewal ability of cancer stem cells may arise from a reprogramming-like mechanism in cells that harbor permissive mutations.

The key questions that arise relate to what mechanisms shared with pluripotency induction participate in tumor formation. This process requires the over-expression of just 4 transcription factors, Oct4, Sox2, Klf4 and c-Myc (the last 2 well known oncogenes) (takahashi, Tanabe et al., 2007). The efficiency of this reprogramming process is extremely low and remains so far as an in vitro phenomenon, since there is no evidence that it can naturally occur in vivo although it was recently shown to be susceptible to experimental in vivo induction [6]. Cell reprogramming is an inefficient and stochastic process, in which the cells must overcome many roadblocks to reach pluripotency, just like malignant transformation. However, much of the nature of these barriers remains unknown.
This hypothesis implies that CSCs could be any cell harboring the right genetic changes, which undergoes an altered reprogramming-like process. Interestingly, the process of iPSC generation is highly inefficient and most cells become trapped into partially reprogrammed states characterized by immortality but not full pluripotency [7]. This mechanism may explain the generation of cancer stem cells from committed progenitors with limited differentiation potential, responsible for the heterogeneous subtypes observed in natural tumors.

Sox2, one of the original Yamanaka cocktail of transcription factors necessary to reprogram somatic adult cells into iPS cells, is a good example of a gene involved in embryonic development whose expression is reactivated during tumor generation. The expression of Sox2 is critical to maintain the pluripotent phenotype in embryonic stem cells and its expression is reactivated during tumor progression. We and others have shown that Sox 2 is expressed in the initial phases of breast tumorigenesis and them is lost as the tumor develops $[8,9]$. This behavior resembles the expression of those genes in pluripotent stem cells that are turned-off as the cells commit to specific lineages. Recently, two seminal papers have demonstrated that Sox $2+$ cells serve as the founding cells for tumor growth and heterogeneity in vivo for medulloblastoma [10] and squamous cell carcinoma [11], thus placing the re-expression of this pluripotency regulator at the root of cancer initiation. This represents a unique opportunity for understanding the onset of cancer but more importantly, points to targeting these mechanisms that control pluripotency regulators expression as potential avenues for novel therapeutic intervention in cancer.

\section{References}

1. Uriel J (1976) Cancer, retrodifferentiation, and the myth of Faust. Cancer Res 36: 4269-75.

2. Chaffer CL, Brueckmann I, Scheel C, Kaestli AJ, Wiggins PA, et al. (2011) Normal and neoplastic nonstem cells can spontaneously convert to a stemlike state. Proc Natl Acad Sci U S A 108: 7950-7955.

3. Vazquez-Martin A, Vellon L, Quirós PM, Cufí S, Ruiz de Galarreta E (2012) Activation of AMP-activated protein kinase (AMPK) provides a metabolic barrier to reprogramming somatic cells into stem cells. Cell Cycle 11: 97489.

4. Riggs JW, Barrilleaux BL, Varlakhanova N, Bush KM, Chan V, et al. (2013) Induced pluripotency and oncogenic transformation are related processes. Stem Cells Dev 22: 37-50.

5. Kawamura T, Suzuki J, Wang YV, Menendez S, Morera LB, et al. (2009) Linking the p53 tumour suppressor pathway to somatic cell reprogramming. Nature 460: 1140-1144.

6. Abad M, Mosteiro L, Pantoja C, Cañamero M, Rayon T, et al. (2013) Reprogramming in vivo produces teratomas and iPS cells with totipotency features. Nature 502: 340-345.

7. Mikkelsen TS, Hanna J, Zhang X, Ku M, Wernig M, et al. (2008) Dissecting direct reprogramming through integrative genomic analysis. Nature 454: 49-55. 
Citation: Martin (2015) Pluripoteny and Cancer, Two Sides of The Same Coin?. Human Genet Embryol 5: 1000e110. doi: 10.4172/2161-0436.1000e110

Page 2 of 2

8. Leis O, Eguiara A, Lopez-Arribillaga E, Alberdi MJ, Hernandez-Garcia S, et al. (2012) Sox 2 expression in breast tumours and activation in breast cancer stem cells. Oncogene 31: 1354-1365.

9. Lengerke C, Fehm T, Kurth R, Neubauer H, Scheble V, et al. (2011) Expression of the embryonic stem cell marker SOX2 in early-stage breast carcinoma. BMC Cancer 11: 42
10. Vanner RJ, Remke M, Gallo M, Selvadurai HJ, Coutinho F, et al. (2014) Quiescent Sox2(+) Cells Drive Hierarchical Growth and Relapse in Sonic Hedgehog Subgroup Medulloblastoma. Cancer Cell 26: 33-47.

11. Boumahdi S, Driessens G, Lapouge G, Rorive S, Nassar D, et al. (2014) SOX2 controls tumour initiation and cancer stem-cell functions in squamous-cell carcinoma. Nature 511: 246-250. 